\title{
Temporal Characteristics and Synoptic Conditions of Extreme Bora Formation in Novorossiysk
}

\author{
V. V. Efimov*, O. I. Komarovskaya, T. M. Bayankina \\ Marine Hydrophysical Institute of RAS, Sevastopol, Russian Federation \\ *vefim38@mail.ru
}

Purpose. Bora in Novorossiysk is the strong, cold, gusting northeast wind directed to the sea on a ridge slope. As the dangerous phenomenon of weather it happens in winter at the wind speed more than $30 \mathrm{~m} / \mathrm{s}$, therefore, bora cases with maximum speed and minimum subzero temperature are of practical and all-physical interest.

Methods and Results. According to long-term daily data from the archives at the station Novorossiysk and observations from the Russian Hydrometeorological Institute (https://rp5.ru/) for the period 1901-2017 statistics on the number of days with bora for cold and warm periods and the number of bora cases with different duration of the day and their repeatability by month for the period 1901-2017 are obtained. Modern regional numerical models developed in the Marine Hydrophysical Institute permit to take into account the role of orography in generation of the Novorossiysk bora, to define its localization and to study evolution of thermodynamic fields of a strong bora during its development and attenuation. The estimation of the repeatability of extreme wind speeds at true bora by the method of approximation of the cumulative function of the series by the Weibull distribution is given. In the analysis of sinoptic features of bora formation, the data of RegCM regional reanalysis for the period 1979-2013, as well as data of ERA Interim reanalysis at model levels were used. Roses of winds for points at windward and leeward slopes are constructed.

Conclusions. It was found that the average annual number of days with bora for the study time series is 30. The greatest duration of cases with bora falls on the winter months and can be up to 7 days. From the arrays of reanalysis data, the fields of pressure and wind speed corresponding to a strong bora are selected and classified by the cluster analysis method. Composites of pressure and wind fields are constructed. It is shown that the condition for the development of a strong bora is the formation of two pressure centers - the northern cyclonic and southern anticyclonic. Vertical profiles of temperature, wind speed and buoyancy frequency for 2 main clusters are presented. According to the measurements on the Novorossiysk HMS, the time characteristics of the bora were estimated. It is shown that the main features necessary for the formation of a true bora is an intense low - atmospheric air flow with velocities of about 10-15 m/c, accompanied by temperature inversion at an altitude of about $1 \mathrm{~km}$ and the formation of the underlying layer of stably stratified air.

Keywords: bora in Novorossiysk, repeatability, cluster analysis, Froude number, buoyancy frequency.

Acknowledgements: the investigation is carried out within the framework of the state task on the theme No. 0827-2018-0001 "Fundamental studies of the interaction processes in the oceanatmosphere system conditioning the regional spatial-temporal variability of natural environment and climate" (code "Ocean and atmosphere interaction").

For citation: Efimov, V.V., Komarovskaya, O.I. and Bayankina, T.M., 2019. Temporal Characteristics and Synoptic Conditions of Extreme Bora Formation in Novorossiysk. Physical Oceanography, [e-journal] 26(5), pp. 361-373. doi:10.22449/1573-160X-2019-5-361-373

DOI: $10.22449 / 1573-160 X-2019-5-361-373$

(C) 2019, V. V. Efimov, O. I. Komarovskaya and T. M. Bayankina,

(C) 2019, Physical Oceanography

\section{Introduction}

The most dangerous weather phenomenon in the cold season on the Black Sea eastern coast is the Novorossiysk Bora - a strong, cold and gusty northeastern wind 
directed towards the sea along the slope of the mountain range. The division of the Novorossiysk Bora into five types (stock, intramass, monsoon, frontal and mixed) [1] is still used in the scientific literature, although it can be attributed to any wind from the mountains, even to the breeze circulation [2]. With this separation, winds also apply to cases in the warm season, when the wind velocity exceeds the conventional level of $15 \mathrm{~m} / \mathrm{s}$. But real or true bora ("true bora is observed only during polar and especially ultra-polar invasions of cold" [2, p. 52]) is accompanied, apart from high velocities, by significant temperature drops (up to $-10,-15^{\circ} \mathrm{C}$ ), leads to large losses in economic activity and is observed only in the cold season. Such a bora can only be called a frontal bora, which is most often repeated in the winter season (having a repeatability of about 73\% [1]) and arises as a result of polar or ultra-polar intrusions of cold air [2].

The most effective method for studying the hydrodynamic processes of bora development is numerical modeling using modern regional atmospheric models [3]. Modeling provided significant supplementation of the understanding of the nature of the bora formation hydrodynamic processes by the example of natural processes developed and described earlier in numerous works on the problem of mountain winds $[4,5]$. It has been shown that bora, as one of the mountain wind types, in the first approximation is determined by the ratio of wind velocity $U$ to mountain height $h$ and buoyancy frequency $N$ in the lower atmosphere level at heights comparable to the mountain height. The Froude number Fr $=U / h N$ is a numerical measure of the mountain air flow regime. Without going into details (see [6]), we note that the necessary conditions for the strong bora development are a high wind velocity and stable stratification of the lower atmosphere level in the region of the windward slope of the mountains. The structure of bora in the region of the leeward slope depends on the Froude number value: at values Fr $<1$, the bora jet stream is pressed against the leeward slope, forming a low-tropospheric flow; otherwise the stream oscillates vertically, forming upstream bora.

An important feature of bora development is associated with the features of the mountains relief. In the south, southward of Tuapse, high Caucasus Mountains are located. The wind flowing from the east and northeast bends around them from the north, leading to an increase in the northeastern wind in the lower part of the atmosphere in the region of the windward slope of the mountains in the Novorossiysk area.

The aim of this work is to study the repeatability characteristics of the Novorossiisk bora using standard measurements at the Novorossiysk hydrometeorological station (HMS), as well as from RegCM climate reanalysis data obtained at the Marine Hydrophysical Institute using a regional numerical model with increased spatial resolution. In this case, the main attention will be paid to the study of the frequency and occurrence conditions of the so-called true bora in the winter season, characterized not only by high velocities, but also by low values of surface air temperature. 


\section{The data used}

The work is based on the Roshydromet (Federal Service of Russia on Hydrometeorology and Monitoring of the Environment) long-term archival data on the Novorossiysk HMS and archive data (https://rp5.ru/) for 1901-2017 (117 years). $\operatorname{Reg} C M^{1}$ reanalysis data for 1979-2013 [7] with a resolution of $25 \mathrm{~km}$ (reduced to a regular grid with a step of $0.11^{\circ}$ ) and ERA-Interim for 1979 to 2017 [9] with a resolution of about $80 \mathrm{~km}$ (reduced to a regular grid with a step of $0.75^{\circ}$ ) were also used. All the used model data have $6 \mathrm{~h}$ time interval.

The archive of wind velocity and direction over a 117-year observation period at the Novorossiysk station is statistically heterogeneous. Wind observations at the Novorossiysk weather station for the entire period were carried out at an altitude of $10 \mathrm{~m}$, which corresponds to the WMO recommendations [10]. From 1901 to 1960 the measurements in the hydrometeorological network were carried out visually using the Wild's anemometer, and from 1961 to the present instrumentally using M47 and M63M1 anemorumbometers and other measuring instruments. For visual observations (over a weather vane), wind velocity and direction were averaged over 2 minutes, and for instrumental observations (since 1961), a 10-minute averaging was carried out (according to WMO requirements, a 10-minute interval for averaging wind velocity is the main characteristic of a stable wind flow over time). In addition, the timing of observations (three-, fourand eight-term) does not coincide. Taking into account these differences, this series of observations (1901-2017) can be divided into two arrays.

The first array (the first period: 1901-1960) was formed according to visual observations (according to the weather vane) [1]. It includes data on years with monthly observations of northeastern winds with $U \geq 15 \mathrm{~m} / \mathrm{s}$ velocity, while a hurricane wind with $U \geq 30 \mathrm{~m} / \mathrm{s}$ velocity is highlighted separately.

The second array (the second period: 1961-2017) includes daily four- and eight-term observations of wind velocity and direction. The nature of the wind velocity diurnal variation is quite well detected already from the data of four-term observations. Therefore, the series of four- and eight-term observations are combined. Missed dates in four-term observations are supplemented by velocity values averaged between time-adjacent measurements.

\section{Analysis results}

Repeatability of bora. We will conditionally consider each year as a combination of cold (from October to March) and warm (from April to September) seasons. Following [1], we will consider a day to be a day with bora if in one of the synoptic periods a northeastern wind of $15 \mathrm{~m} / \mathrm{s}$ velocity or more was observed. If the northeastern wind blew a day or more, then this the time interval will be considered as a case of bora. For all seasons in each measurement period the data were sampled with the indicated wind parameters and the number of days with bora was calculated, as well as their repeatability. The results are given in Table 1.

1 Efimov, V.V., Barabanov, V.S., Yarovaya, D.A., Yurovsky, A.V. and Bayankina, T.M., 2017. [An Array of Data on Numerical Reanalysis of the Atmospheric Circulation Characteristics of the Black Sea-Caspian Region for 1979-2013 Period]. [electonic database] Sevastopol: MHI RAS (in Russian).

PHYSICAL OCEANOGRAPHY VOL. 26 ISS. 5 (2019) 
Number of days with bora in Novorossiysk during the periods 1901-1960 and $1961-2017$ in cold and warm seasons and its repeatability

\begin{tabular}{c|r|c|c|c}
\hline \multirow{2}{*}{ Season } & \multicolumn{2}{|c|}{ The first period (1901-1960) } & \multicolumn{2}{c}{ The second period (1961-2017) } \\
\cline { 2 - 5 } & $\begin{array}{c}\text { Number of } \\
\text { the bora } \\
\text { days }\end{array}$ & Repeatability, \% & $\begin{array}{c}\text { Number of } \\
\text { the bora } \\
\text { days }\end{array}$ & Repeatability, \% \\
\hline $\begin{array}{c}\text { Cold } \\
\text { (October - March) }\end{array}$ & 1245 & 11.4 & 1265 & 12.2 \\
\hline $\begin{array}{c}\text { Warm } \\
\text { (April - September) }\end{array}$ & 557 & 5.1 & 394 & 3.8 \\
\hline
\end{tabular}

The obtained results (Table 1) show that in the cold season the number of days with bora and their frequency in both periods differ slightly (less than 1\%). In the warm season, in the first period the number of days with bora is $1.3 \%$ more than in the second one. The difference between these estimates of the number of days with bora is statistically insignificant. The average annual number of days with bora for the studied 117-year time series is 30. This value is close to the following source estimates: 32 days [1], 45 days [2, 3] and from 30 to 40 days [11]. It should be noted that the actual picture of the bora cases distribution in some years significantly differs from the average one. In Table 2 the statistical data on years with the maximum and minimum number of days with bora are given.

T a b l e 2

The years containing the bora days the number of which exceeds or equals 40 and is lower or equals 10

\begin{tabular}{|c|c|c|c|c|}
\hline Periods & $\begin{array}{c}\text { Years when bora } \\
\text { was observed } 40 \\
\text { and more days per } \\
\text { year }\end{array}$ & $\begin{array}{l}\text { Maximum } \\
\text { number of bora } \\
\text { days (year) }\end{array}$ & $\begin{array}{c}\text { Years when bora } \\
\text { was observed } 10 \\
\text { and more days } \\
\text { per year }\end{array}$ & $\begin{array}{c}\text { Minimum } \\
\text { number of bora } \\
\text { days (year) }\end{array}$ \\
\hline $1901-1960$ & $\begin{array}{l}1904,1907,1911, \\
1919,1920,1921, \\
1924,1927,1928, \\
1929,1953,1954\end{array}$ & $\begin{array}{l}66 \text { (1929); } \\
68 \text { (1953) }\end{array}$ & 1908, 1923, 1938 & $2(1923)$ \\
\hline 1961-2017 & $\begin{array}{c}1972,1976,1977 \\
1980,1984,1987 \\
2002,2003,2005 \\
2008,2014\end{array}$ & $54(1976)$ & $\begin{array}{l}1962,1964, \\
1965,1966, \\
1967,1989\end{array}$ & $3(1965)$ \\
\hline
\end{tabular}

$\mathrm{N}$ o $\mathrm{t}$ e: The data for 1901-1954 are from [1], for 1955-2017 - from the observations at the Novorossiysk HMS 
The distribution of the average number of days with bora by months is represented in Table 3. From Table 3 it follows that the average monthly number of days with bora in the cold season is up to 3 days, the minimum air temperature drops to $-20{ }^{\circ} \mathrm{C}$. Now we consider the measurement data in terms of the number of bora cases and the duration of each case (Table 4).

The season from September to March accounts for $76.4 \%$ of all bora cases and the one from April to August - 23.6\%. The obtained results are close to the estimates given in [1]. The longest average duration of cases with bora occurs in the winter months (up to 7 days), the minimum - in the summer months (up to 1- 2 days) (Table 4). But, as mentioned above, the cases of bora with maximum velocity and minimum negative temperature are of the greatest practical and general physical interest. Such cases of true bora will be considered in more detail below.

$\mathrm{Tab}$ a 3

Monthly average number of the bora days and minimum air temperature during bora in 1901-2017

\begin{tabular}{|c|c|c|c|c|c|c|c|c|c|c|c|c|}
\hline \multirow{2}{*}{ Parameters } & \multicolumn{12}{|c|}{ Months } \\
\hline & I & II & III & IV & $\mathrm{V}$ & VI & VII & VIII & IX & $X$ & XI & XII \\
\hline $\begin{array}{l}\text { Average } \\
\text { number of bora } \\
\text { days }\end{array}$ & 2.7 & 2.6 & 2.4 & 2.0 & 1.9 & 1.4 & 1.5 & 1.8 & 2.4 & 2.7 & 2.8 & 2.9 \\
\hline $\mathrm{T}_{\min },{ }^{\circ} \mathrm{C}$ & -19.3 & -19.8 & -10.1 & 0.0 & 5.8 & 15.4 & 15.6 & 15.0 & 5.5 & -3.5 & -9.3 & -18.9 \\
\hline
\end{tabular}

Table 4

Monthly distribution of a number of the bora cases in 1901-2017

\begin{tabular}{l|r|r|r|r|r|r|r|r|r|r|r|r}
\hline \multirow{2}{*}{ Parameters } & \multicolumn{10}{|c}{ Months } \\
\cline { 2 - 12 } & I & II & III & IV & V & VI & VII & VIII & IX & X & XI & XII \\
\hline Bora duration, day & & & & & & & & & & & & \\
$1-2$ & 412 & 124 & 141 & 103 & 71 & 35 & 47 & 62 & 98 & 137 & 128 & 105 \\
$3-4$ & 13 & 84 & 21 & 13 & 9 & 4 & 3 & 7 & 30 & 36 & 35 & 43 \\
$5-6$ & 3 & 2 & 4 & 0 & 1 & 0 & 0 & 0 & 2 & 4 & 3 & 11 \\
$\geq 7$ & 169 & 177 & 174 & 118 & 83 & 39 & 50 & 69 & 135 & 177 & 170 & 162 \\
\hline $\begin{array}{l}\text { General amount of } \\
\text { bora cases }\end{array}$ & 16 & & & & & & & & & & & \\
\hline $\begin{array}{l}\text { Monthly } \\
\text { repeatability of } \\
\text { bora, \% }\end{array}$ & 4.7 & 5.4 & 4.8 & 3.4 & 2.3 & 1.1 & 1.4 & 1.9 & 3.8 & 4.9 & 4.8 & 4.5 \\
\hline
\end{tabular}


In order to assess the repeatability of wind velocity at true bora, wind velocities of at least $15 \mathrm{~m} / \mathrm{s}$ at an air temperature of not more than $-5{ }^{\circ} \mathrm{C}$ for four months of the cold season from December to March were selected from the available instrumental measurement data at Novorossiysk HMS for 1961-2017. To assess the repeatability of extreme wind velocities, the cumulative distribution of the wind velocity $F(U)$ function should be known. Weibull theoretical distribution is generally accepted, which agrees well with the observational results. Weibull distribution function has the following form: $F=1-\left[\exp (-U / \lambda)^{k}\right]$, where $\lambda>0$ is the scale parameter; $k>0$ is a parameter of the Weibull distribution form. A graph of cumulative distribution function in the coordinates of the Weibull distribution, represented in Fig. 1, is constructed according to basic series.

The straight line is the trend line drawn in our case by the least squares method, which corresponds to the Weibull distribution in coordinates $\ln (-\ln (1-F(U)))$ and $\ln (U)$, where $U$ is the wind velocity. As can be seen, it closely approximates the experimental distribution function. The slope of the line is determined by the value of $k$ parameter, the point of intersection with the abscissa axis is calculated by the formula $k \ln (\lambda)$. In our case $\lambda=4,69$ and $k=1,29$. Table 5 represents the repeatability values estimated from the initial series of measurements $P=m /(n+1)$ where $n$ is the length of the series under consideration, and the $m^{\text {th }}$ observation in ascending order fixes the value for which repeatability is calculated), and according to the approximating distribution (repeatability $P=1-F(U)$, repeatability period $T=1 /[1-F(U)]$ ) for large values of bora velocity.

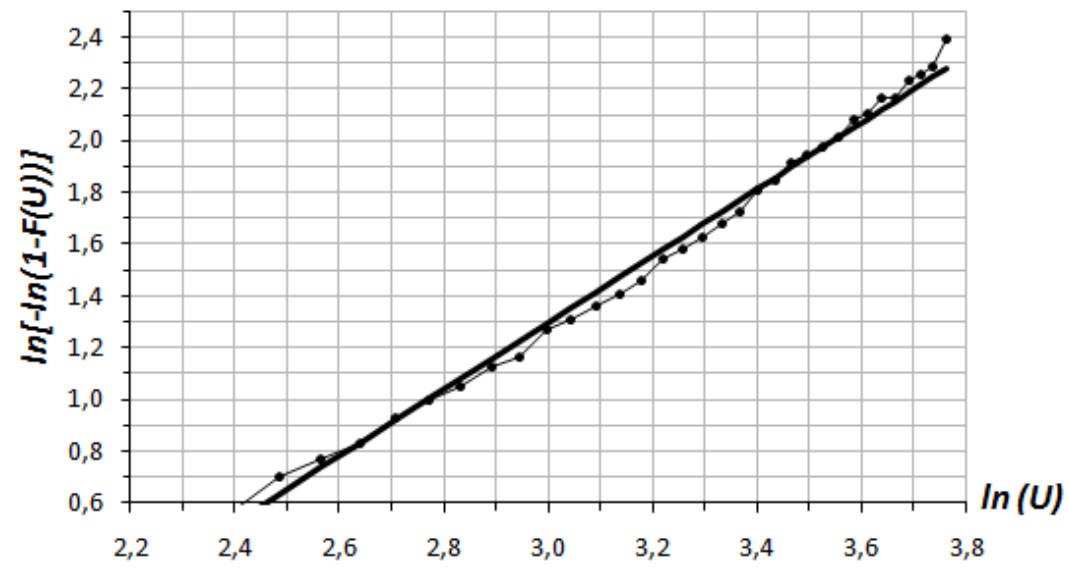

F i g. 1. Approximation of the cumulative function of wind velocity distribution by the Weibull distribution 
Repeatability of high wind velocities during bora

\begin{tabular}{l|c|c|c|c|c|c}
\hline \multirow{2}{*}{ Parameters } & \multicolumn{7}{|c}{ Wind velocity $U, \mathrm{~m} / \mathrm{s}$} \\
\cline { 2 - 7 } & 20 & 25 & 30 & 35 & 40 & 45 \\
\hline $\begin{array}{l}\text { Repeatability calculated } \\
\text { by a series, \% }\end{array}$ & 2.880 & 0.940 & 0.220 & 0.056 & 0.009 & 0.002 \\
\hline $\begin{array}{l}\text { Repeatability calculated by } \\
\text { the Weibull distribution, \% }\end{array}$ & 2.640 & 0.790 & 0.220 & 0.056 & 0.014 & 0.003 \\
\hline $\begin{array}{l}\text { Repeatability } \\
\text { period based on the } \\
\text { Weibull distribution }\end{array}$ & $\begin{array}{c}19 \\
\text { (days) }\end{array}$ & $\begin{array}{c}65 \\
\text { (days) }\end{array}$ & $\begin{array}{c}234 \\
\text { (days) }\end{array}$ & $\begin{array}{c}2.47 \\
\text { (years) }\end{array}$ & $\begin{array}{c}10.1 \\
\text { (years) }\end{array}$ & $\begin{array}{c}43.4 \\
\text { (years) }\end{array}$ \\
\hline
\end{tabular}

Synoptic features of bora formation. Wind roses constructed according to the Novorossiysk HMS data, as well as according to the regional reanalysis RegCM data with increased resolution for the point, located in the steppe part of the windward slope of the Caucasus mountains near Rostov-on-don, i.e. in the area of the oncoming mountain stream, forming a bora, are shown in Fig. 2, $a, c$. The wind rose constructed according to $\mathrm{RegCM}$ reanalysis in the nearest point to HMS Novorossiysk located on the sea is shown in Fig. 2, $b$.

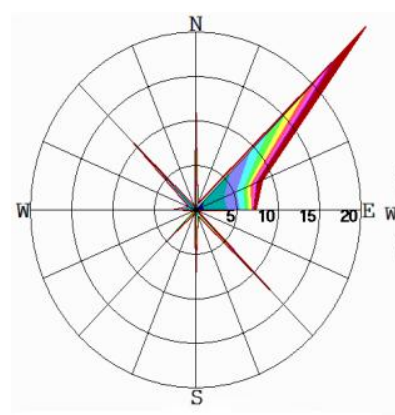

a
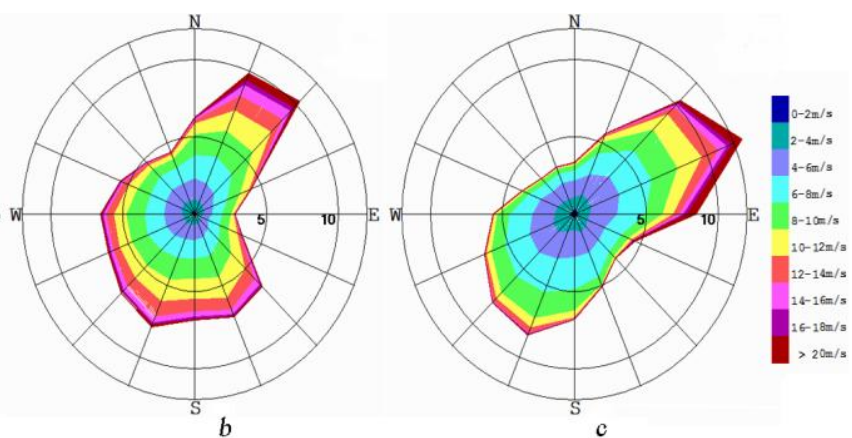

F i g. 2. Wind roses constructed based on the data of the Novorossiysk HMS ( $a$ ), the RegCM reanalysis for the point closest to the Novorossiysk station $(b)$, and for the point close to Rostov-onDon $(c)$

In Novorossiysk the northeasterly direction of the wind prevails, including the katabatic wind from the mountains and bora. In the foothill part, such sharp predominance is absent, although the north-eastern winds have the greatest frequency. We note that the predominance of northeastern winds is characteristic of the entire northern part of the Black Sea region [12], in the foothill part it is enhanced by orographic occlusion - the effect of flow around the northeastern edge of the Caucasus Mountains. The differences in Fig. 2, $a$ and Fig. 2, $b$ are due to insufficient 
spatial resolution of $\operatorname{RegCM}$ model, which does not reconstruct small-scale spatial features of the wind velocity field in the bora. In addition, the measurements of the wind direction at HMS are given with a resolution of $22.5^{\circ}$.

Further we consider the synoptic conditions for the formation of winds of the prevailing eastern and north-eastern directions in the leeward slope of the mountains, well represented on the wind rose (Fig. 2,c). For these purposes we will construct composites of meteorological fields illustrating the formation of masses of cold air intruding from the northeast into the Black Sea in the Novorossiysk region, under which the conditions for true bora development are satisfied, i.e. the wind velocity $U$ is at least $15 \mathrm{~m} / \mathrm{s}$ at negative temperature $T$ no more than $-5^{\circ} \mathrm{C}$.

Using the cluster analysis method ${ }^{2}$ (K-means method [13]), we construct spatial composites characterizing typical average fields of atmospheric pressure and wind velocity during the bora. In Fig. 3 two main spatial clusters of surface pressure and surface wind velocity vectors are shown. Clusters are the result of selective averaging of those 165 fields for which the average daily wind velocities and temperatures of Novorossiysk bora satisfy the indicated restrictions. Fields are selected according to measurements on Novorossiysk HMS from ERA-Interim reanalysis data [9] from 1979 to 2017.

A visual assessment of the selected fields showed the reasonability of dividing into two clusters: the results of dispersive analysis indicate good quality of clustering (the Euclidean distance between the clusters and the values of the $F$ criterion are quite large, and the significance level of the parameters does not exceed a hundredth of a percent). Experiments with a dividing into three or more clusters were also carried out, but their statistical evaluation showed a decrease in the Euclidean distance between the clusters and the values of the $F$-criterion, which indicates deterioration in the quality of the dividing.

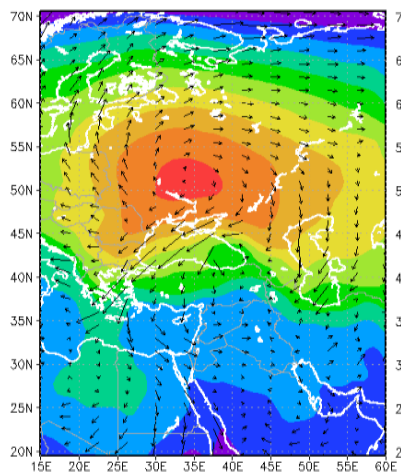

a

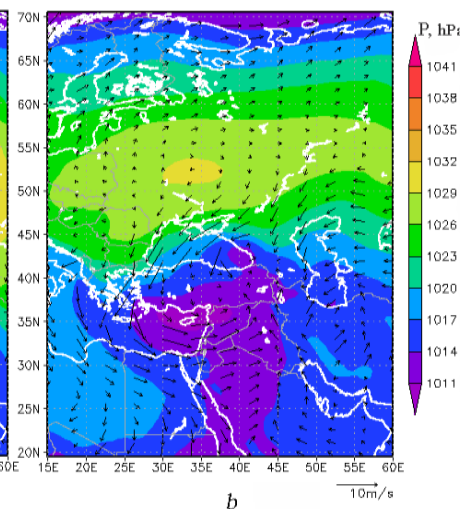

F i g. 3. Composites of the surface pressure and wind speed fields separated by the cluster analysis method for the bora cases at $T<-5^{\circ} \mathrm{C}$ and $U \geq 15 \mathrm{~m} / \mathrm{s}$ based on the Novorossiysk HMS data: $a-$ the first cluster, $b$ - the second cluster

\footnotetext{
${ }^{2}$ StatSoft, 2019. [Electronic Textbook on Statistics]. [online] Available at: http://statsoft.ru/home/textbook/modules/stcluan.html [Accessed: 02.08.2019] (in Russian).
} 
The main element of the first composite (Fig. 3, a) averaging 102 cases of bora at $T<-5{ }^{\circ} \mathrm{C}$ and $U \geq 15 \mathrm{~m} / \mathrm{s}$ is an anticyclone with a center located northward of the Black Sea, on the southeastern periphery of which a northeastern stream of cold air with high velocities of near-surface wind is formed. The second composite (Fig. 3, b) is the result of selective averaging of a smaller number of fields (63) corresponding to bora. Its main element is a southern cyclone with a center in the region of Asia Minor. This composite also includes a weaker, compared with the first composite, northern anticyclone with a center located northward of the Black Sea. Intense true bora forms on the northeastern periphery of the cyclone (second composite) and the southeastern periphery of the anticyclone (first composite). This frontal-type bora is the most repeated in the cold season: the examined 165 cases of true bora accounted for $85 \%$ of the total number of bora cases in these months without limitation on the minimum temperature or $90 \%$ of the number of bora cases with a minimum temperature of $T_{\min }<-5{ }^{\circ} \mathrm{C}$ and $100 \%$ at $T_{\min }<-10{ }^{\circ} \mathrm{C}$.

The physical mechanisms of bora development are determined by the vertical structure of air flux velocity and temperature in the area in front of the windward slope of the mountains, topping over which the bora is formed. In Fig. 4 vertical profiles of air temperature, wind velocity components and buoyancy frequency are represented. The profiles are constructed using the data at model levels of ERAInterim reanalysis [9], averaged for the first (Fig. 3, a) and the second (Fig. 3, b) cluster of bora.

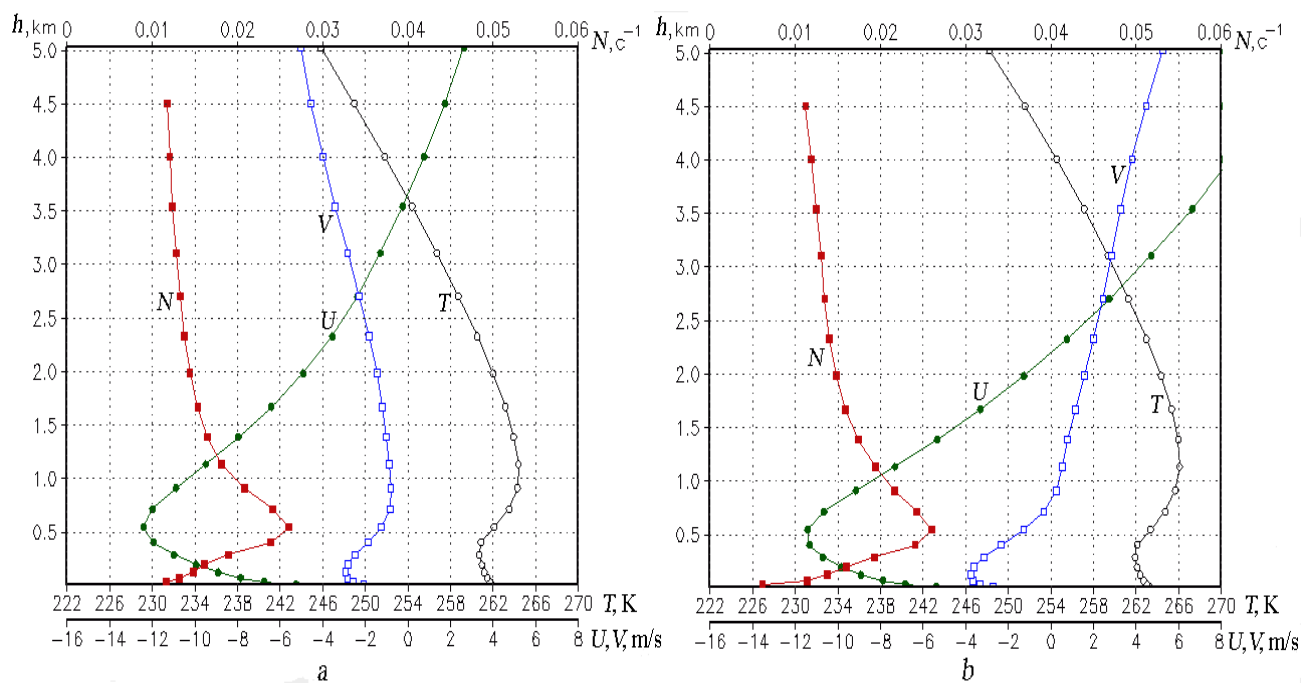

F i g. 4. Average vertical profiles of the air temperature $T$, meridian $U$ and zonal $V$ components of the wind speed and the buoyancy frequency $N$ in the point $\left(45^{\circ} \mathrm{N}, 40^{\circ} \mathrm{E}\right)$ based on the data of the ERA-Interim reanalysis on the model levels [9] for the first $(a)$ and the second $(b)$ bora clusters

As can be seen, in the both cases the air flux has the form of an intense lowtropospheric air flow with $\sim 10-15 \mathrm{~m} / \mathrm{s}$ velocities, having a temperature inversion 
at $\sim 0.5-1 \mathrm{~km}$ altitudes, correspondingly, a maximum in the profile of buoyancy frequency $N$ at a height of $\sim 0,5 \mathrm{~km}$ close to the height of the mountain ranges.

In both cases, at the altitudes of up to $1.5 \mathrm{~km}$ the meridional wind velocity reached large values of $\sim 10-15 \mathrm{~m} / \mathrm{s}$, which was a necessary condition for the development of true bora [6]. The second necessary condition for the bora development is a strong hydrostatic stability of the air flux in the lower part of the troposphere [6].

As follows from Fig. 4, the Froude number estimate in the region of heights comparable with the one of the ridge is $\mathrm{Fr} \approx 1-1.2$. Note that this value is located at the boundary of two bora regimes: a shallow but more intense bora at values of Fr $<1$ and high at Fr $>1[14,15]$. For the first regime, the effects of blocking the flux over the windward slope of the mountains, as well as the development of the critical layer and the turbulent region over the leeward slope, are important. Shallow bora has the nature of a jet of air adjacent to the surface of the leeward layer. For the second bora regime, behind the leeward slope it is detached from the slope surface and has the character of a height-meandering flux. It is interesting to note that during one episode of bora, which lasts 1-2 days, these two modes can alternate as a result of insignificant changes in the velocity $U$ and buoyancy frequency $N$. An example of such behavior of Novorossiisk bora was reconstructed in [5].

Thus, at up to $\sim 1 \mathrm{~km}$ heights the differences in the temperature and velocity profiles for two clusters characterizing the averaged synoptic picture of the true bora formation are small. At higher altitudes, as can be seen from Fig. 4, the differences in the velocity profiles are manifested due to the synoptic features of the velocity and pressure fields that make up the two clusters. In the first of them, an increase in the southward component of the meridional velocity is observed at the periphery of the anticyclone. In the second, where the southern cyclone predominates, on the contrary, the cyclonic velocity component increases with height.

The obtained spatial fields of two predominant clusters and the corresponding vertical profiles of velocity and temperature are the result of averaging a large number of synoptic situations of bora. Selective fields for individual bora cases will differ from them due to the natural synoptic variability. Therefore, the given clusters represent the first two components of the decomposition of intense bora fields for 1979-2017. Note that subsequent clusters for the selected spatial region and a relatively small number of bora cases are statistically insignificant and we do not consider them.

\section{Conclusion}

According to the data on the velocity, wind direction and air temperature obtained at the Novorossiysk HMS over a long period of 1901-2017, the temporal characteristics of bora were estimated. The average monthly number of days with bora was determined. It is calculated that the autumn-winter season (from September to March) accounts for about $76.4 \%$ of cases of bora, and the spring370

PHYSICAL OCEANOGRAPHY VOL. 26 ISS. 5 (2019) 
summer season (April to August) - 23.6\%. The repeatability and average monthly duration of bora were estimated.

The main attention is paid to the cases of strong, so-called true bora. A cumulative function is constructed, and the Weibull distribution parameters for wind velocity are assessed, and estimates of bora repeatability with given velocities in the range of negative air temperatures are given. It has been shown that in the cold period from December to March, true bora is a frontal-type bora that develops on the periphery of the northern anticyclone and southern cyclone. The spatial structures of the first two clusters identified in the data array corresponding to the true bora cases are estimated.

The vertical structure of the fields of wind velocity, temperature and buoyancy frequency in the area in front of the windward slope of the mountains is considered. It is shown that the main feature of true bora is an intense lowtropospheric air flow at 10-15 m/s velocity, accompanied by temperature inversion at a height of $\sim 1 \mathrm{~km}$ and the formation of an underlying layer of stably stratified air. The value of the Froude number at heights comparable with the height of the mountains is $\sim 1$, i.e. it is located in the boundary region that separates the hydrodynamic regimes of bora. The consequence of this is the possibility of the development of the Novorossiysk frontal bora of two types - a shallow intense near-surface air flux or an air flux raised above the surface of the leeward slope, experiencing vertical wave oscillations.

\section{REFERENCES}

1. Gusev, A.M., ed., 1959. [Bora of Novorossiysk]. In: MHI, 1959. [Proceedings of the Marine Hydrophysical Institute]. Moscow: AS USSR Publ. Vol. 14, 140 p. (in Russian).

2. Vasiliev, A.A., Vil'fand, R.M. and Golubev, A.D., 2016. The Joint Use of Mesoscale Numerical and Conceptual Models in Operational Forecast of Hazard Weather Phenomena. In: A. A. Vasiliev, Ed., 2016. Proceedings of Hydrometcentre of Russia. Moscow: Hydrometcentre of Russia. Iss. 359, pp. 48-57. Available at: http://method.meteorf.ru/publ/tr/tr359/vasiliev.pdf [Accessed: 20 March 2019] (in Russian).

3. Gavrikov, A.V. and Ivanov, A.Y., 2015. Anomalously Strong Bora over the Black Sea: Observations from Space and Numerical Modeling. Izvestiya, Atmospheric and Oceanic Physics, [e-journal] 51(5), pp. 546-556. https://doi.org/10.1134/S0001433815050059

4. Vil'fand, R.M., Rivin, G.S and Rozinkina, I.A., 2010. COSMO-RU System of Nonhydrostatic Mesoscale Short-range Weather Forecast of the Hydrometcenter of Russia: the First Stage of Realization and Development. Russian Meteorology and Hydrology, [e-journal] 35(8), pp. 503-514. https://doi.org/10.3103/S1068373910080017

5. Efimov, V.V. and Barabanov, V.S., 2013. Simulation of Bora in Novorossiysk. Russian Meteorology and Hydrology, [e-journal] 38(3), pp. 171-176. https://doi.org/10.3103/ S1068373913030059

6. Efimov, V.V. and Komarovskaya, O.I., 2018. Seasonal Variability and Hydrodynamic Regimes of the Novaya Zemlya Bora. Izvestiya, Atmospheric and Oceanic Physics, [e-journal] 54(6), pp. 581-593. https://doi.org/10.1134/S0001433818060051 
7. Anisimov, A.E., Yarovaya, D.A. and Barabanov, V.S., 2015. Reanalysis of Atmospheric Circulation for the Black Sea-Caspian Region. Physical Oceanography, [e-journal] (4), pp. 13-25. doi:10.22449/1573-160X-2015-4-13-25

8. Dee, D.P., Uppala, S.M., Simmons, A.J., Berrisford, P., Poli, P., Kobayashi, S., Andrae, U., Balmaseda, M.A., Balsamo, G. and Bauer, P. [et al.], 2011. The ERA-Interim Reanalysis: Configuration and Performance of the Data Assimilation System. Quarterly Journal of the Royal Meteorological Society, [e-journal], 137(656), pp. 553-597. doi:10.1002/qj.828

9. Shaimardanov, V.M., 2011. Organization of Quality Control of Information Including in the Data Fund. In: V. M. Kattsov, E. L. Genihovich, A. S. Zaitsev, I. L. Karol, N. V. Kobysheva, V. P. Meleshko, A. V. Mescherskaya, O. M. Pokrovcky and C. C. Chicherin, eds., 2011. Proceedings of Voeikov Main Geophysical Observatory. Vol. 564, pp. 166-177 (in Russian).

10. Alpers, W., Ivanov, A. and Horstmann, J., 2009. Observations of Bora Events over the Adriatic Sea and Black Sea by Spaceborne Synthetic Aperture Radar. Monthly Weather Review, [e-journal] 137(3), pp. 1150-1161. https://doi.org/10.1175/2008MWR2563.1

11. Semenov, E.K., Sokolikhina, N.N. and Sokolikhina, E.V., 2013. Meteorological and Synoptic Aspects of the Formation and Evolution of the Novorossiysk Bora. Russian Meteorology and Hydrology, [e-journal] 38(10), pp. 661-668. https://doi.org/10.3103/S1068373913100026

12. Hartigan, J.A. and Wong, M.A., 1979. Algorithm AS 136: A K-Means Clustering Algorithm. Journal of the Royal Statistical Society. Series C (Applied Statistics), [e-journal] 28(1), pp. 100-108. https://doi.org/10.2307/2346830

13. Smith, R.B., 1989. Hydrostatic Airflow over Mountains. Advances in Geophysics, [e-journal] 31, pp. 1-41. doi:10.1016/S0065-2687(08)60052-7

14. Eckermann, S.D., Lindeman, J., Broutman, D., Jun, Ma and Boybeyi, Z., 2010. Momentum Fluxes of Gravity Waves Generated by Variable Froud Number Flow over Three-Dimentional Obstacles. Journal of the Atmospheric Sciences, [e-journal] 67(7), pp. 2260-2278. https://doi.org/10.1175/2010JAS3375.1

\section{About the authors:}

Vladimir E. Efimov - Head of Atmosphere and Ocean Interaction Department, Marine Hydrophysical Institute of RAS (2 Kapitanskaya Str., Sevastopol, 299011, Russian Federation), Dr.Sci. (Phys.-Math.), Professor, ResearcherID: P-2063-2017, Scopus Author ID: 6602381894, vefim38@mail.ru

Olga I. Komarovskaya - Research Associate, Marine Hydrophysical Institute of RAS, (2 Kapitanskaya Str., Sevastopol, 299011, Russian Federation), ResearcherID: G-1814-2019, komarovskaya@mhi-ras.ru

Tat'yana M. Bayankina - Research Associate, Marine Hydrophysical Institute of RAS, (2 Kapitanskaya Str., Sevastopol, 299011, Russian Federation), Ph.D. (Geogr.), ResearcherID: G-2535-2019, bayankina@mhi-ras.ru

Contribution of the co-authors:

Vladimir E. Efimov - statement of the problem, interpretation of the results

Olga I. Komarovskaya - numerical modeling

Tat'yana M. Bayankina - statistics of bora field observations by HMS Novorossiysk 
All the authors have read and approved the final manuscript.

The authors declare that they have no conflict of interest. 